\title{
LXV. On the velocity of sound
}

\section{W. Galbraith Esq. M.A.}

To cite this article: W. Galbraith Esq. M.A. (1827) LXV. On the velocity of sound, Philosophical Magazine Series 2, 1:5, 336-339, DOI: 10.1080/14786442708674323

To link to this article: http://dx.doi.org/10.1080/14786442708674323

曲 Published online: 10 Jul 2009.

Submit your article to this journal

Џ Article views: 2

Q View related articles $₫$ 
the water (on which the effect depends) being diminished by the mixture of the alcohol, is not apparent.

Another singular example of the agency of heat in effecting a diminution of corpuscular attraction presents itself in the following experiment:-Cut two pieces of soft lead, so that each may have a plain and bright surface; by pressure these surfaces may be made to cohere with considerable force. Suspend the pieces one perpendicularly over the other, and to the lower piece hang weights, nearly as heavy as the cohesive force may be supposed capable of supporting. 'The application of a degree of heat, not superior to that of boiling water, will canse a separation, provided the weights be sufficiently heavy: whence the corpuscular force of heat produces sensible effects at minute, even sensible distances.

The phænomena of the capillary action of parallel metallic plates are curious. I have made a considerable number of experiments; but until some difficulties shall be surmounted, they cannot be in a state to be submitted to public scrutiny.

An apology is due to you as well as to your readers, for the delay-after I had promised to continue the subject in your last Number: however, I am certain it will not be required, when it is considered that the manufacture of all my own apparatus, which the small resources of a country curacy make requisite, often requires ten times the time which the experimental researches occupy. In addition, the discovery that the column is suspended by the upper stratum only, rendered the experiments of several weeks quite useless, and demands the application of apparatus of a new construction, which is now nearly complete.

[To be continued.]

LXV. On the Velocity of Sound. By W.Galbraytrh, Esq.M.A.

\section{To Richard Taylor, Esq.}

Sir,

N the 68th volume of the Philosophical Magazine, page 214,

I gave a short paper On the velocity of sound transmitted through the atmosphere. In it I endeavoured to investigate an accurate and commodious formula for determining the velocity of sound under given circumstances, embracing all those minutia affecting it, so far as I was acquainted with them. In a note, (pages 215 and 216,) I mentioned the values of the constant generally introduced in the late investigations of this question, and hinted that a mean of the whole of these, namely 1.4112, was more conformable to the velocity of sound by ex-

periment, 
periment, than that (1.362) which I had usually supposed the more accurate. Now if this be introduced into formula (4), page 217 , and the proper value for $g$ also, a slight modification will be effected in the general formulæ for the velocity in metres or English feet.

$$
\mathrm{V}=(105.9518+0.19845 t)\left(1+\frac{f}{5 \frac{1}{3} p-2 f}\right)(3 \cdot 14143-
$$

$0.0042 \cos 2 \lambda)+\omega \cos \phi \ldots \ldots \ldots \ldots(A)$

the velocity in metres using the metrical barometer and centigrade thermometer.

$$
\begin{aligned}
\mathrm{V}= & \left\{105.9518+0.1103\left(t-32^{\circ}\right)\right\}\left(1+\frac{f}{5 \frac{1}{3} p-2 f}\right)(10.2739 \\
& -0.01378 \cos 2 \lambda)+\omega \cos \varphi \ldots \ldots \text { (B) }
\end{aligned}
$$

the velocity in English feet, employing the English barometer and Fahrenheit's thermometer.

As I have been able to find no experiments by which a direct comparison with these formulæ can be made, except those of Professor Moll of Utrecht, with the omission of the last term, namely, $\omega \cos \phi$, I cannot say whether it is in this last respect perfectly correct. As Dr. Moll took the precantion of firing guns at each end of the measured base, the effect of the wind was in this case obviated; and if my formula agree nearly with his experiments, independent of this term, it may be looked on in this state as verified by direct experiment.

The truth of these remarks will be obvious, on consulting Dr. Moll's paper in the Philosophical Transactions of the Royal Society of London for the year 1824, pages 425, \&c. in which a full account of the whole steps of his experiments is recorded. At page 445 there is presented a table of the velocity of sound from 44 different experiments on a base near Utrecht in Holland, of about nine miles in length. On the 27 th of June 1823, twenty-two shots were fired at each station or end of the base of 17669.28 metres, or 9664.7044 fathoms, the metre being supposed 39.3824 English inches. The sum of the times was $2286^{5} \cdot 07$, which divided by 44 gives $51^{\text {s. }} 96$ for the mean of the whole, which Dr. Moll adopts. Whence $\frac{17669 \cdot 28}{51 \cdot 96}=340 \cdot 06$ metres; the experimental velocity in one second of time. Now while these 22 shots were fired at each end of the measured base, the mean temperature at both ends of it was $11^{\circ} \cdot 16=t$ of the Centigrade scale. Also the mean height of the metrical barometer was $744475=p$; the mean tension of aqueous vapour by Daniell's hygrometer was 0.00925307 metre $=f$. By substituting these quantities in formula (A) neglecting the last term, $\omega \cos \phi$, since by fring guns at both ends of the measured base its effect, as Nero Series. Vol. 1. No. 5. May 182\%. $2 \mathrm{X}$ Dr. 
Dr. Moll observes, page 425, was " annihilated,"-we have, $(105 \cdot 9518+2 \cdot 2147)\left(1+\frac{0.0092531}{3 \cdot 972-0.0185}\right)(3 \cdot 1.3143+0.00105)=$ $108.1665 \times 1.0023 \times 3.13248=339.622$ metres.

Experiment gives ..... 340.0 3406

Error of formula ....... $-\overline{-0.438}$ metre.

In like manner if we compare 14 shots at each end of the base, or 28 at both, fired on the 28th of June 1823, we have,

$108 \cdot 17742 \times 1 \cdot 00212 \times 3 \cdot 13248=339 \cdot 582$ metres.

Experiment gives . . . . . 339.34

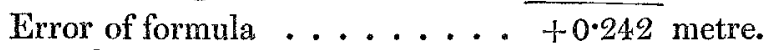

Whence, these errors being of different signs, we may conclude that it is probable the formula agrees very well with Dr. Moll's experiments, as the mean error of the whole would only be about -0.196 of a metre, or about eight English inches; a degree of coincidence, in such researches, not to be expected.

Though Dr. Moll has not stated the effect of the wind, yet it may, I think, be inferred from his observations made at each end of the base alternately, as on the 25th and 26 th of June 1823.

On the first day, the velocity was 337.39 metres.

On the second ....... 346.59

Difference .......... $\frac{34.20}{9 .}$ metres, or about 30 English feet.

The same conclusion may be drawn from his experiments when the guns were fired, and heard at both stations.

Thus on the 27 th of June 1823, Phil. Trans. 1824, p. 445,

The mean of the one column II. is $\frac{1162^{s} \cdot 37}{22}=\ldots 52^{s} \cdot 835$

The mean of column III. is ... $\frac{1123^{\mathrm{s}} \cdot 07}{22}=\ldots 51^{\mathrm{s} \cdot 049}$

Difference in time is . . . . . . . . $\overline{1 \cdot 786}$

Now, $\frac{17669^{\mathrm{m}} \cdot 28}{52^{\mathrm{s}} \cdot 835}=334 \cdot 424$ metres,

And, $\frac{17669^{\mathrm{m}} \cdot 28}{51^{\mathrm{s}} \cdot 049}=346 \cdot 124$

Difference . . $=\overline{11 \cdot 700}$ "metres, or about 38 English feet per second, according as the velocity is determined from the one end of the base, or the other.

Now for want of other evidence, we may reasonably suppose that this is occasioned by the effect of the wind accelerating the sound in the one case, and retarding it in the other. Direct experiments are, however, still wanting to settle this point in an unobjectionable manner, though from the state to which 
which the investigation is now brought, we may shortly expect the most decisive proof of its just effect. I am, Sir, \&c.

Edinburgh, Jan. 21, 1827.

WM. Galbiraith.

P.S. I have since found that the coefficients to the formula may vary on account of the different states of the atmosphere. The quantity by which the formula of Newton before extracting the root should be multiplied, may vary from 1.3 to 1.5 , making that adopted lately by M. Laplace, or 1.4, the mean. Therefore 1.3 must be the quantity in very $d r y$ air, 1.4 in moist, and 1.5 in very damp.

Hence my coefficients should be

$$
\left.\begin{array}{l}
\text { Dry . . 103 } \\
\text { Moist . . 106 instead of } 104 \cdot 0885 \\
\text { Damp . . 109 }
\end{array}\right\} \text { or even } 105 \cdot 9518 \text {. }
$$

I have come to these conclusions in the mean time, but shall return to the subject at some convenient opportunity. W. G.

LXVI. Results of the Meteorological Observations made at Wick in the northernmost part of Scotland, published in the Philosophical Magazine. By W. Burner, LL.D.

To the Editors of the Philosophical Magazine and Annals of Gentlemen, philosophy.

YOU have inserted in your Magazine and Annals, two articles containing Meteorological Observations made at Wick, in the county of Caithness, in the years 1823 and 1825; and as no observations of this kind have been sent to you before from that remote part of Scotland, I have thought their results would be acceptable to those of your readers who are interested in meteorology, by the way of comparison; and have therefore made up their results in two concise tables, with occasional remarks. Seeing some discrepancies in the results of the first article, and knowing that you are very correct in printing, $l$ was induced to go over the calculations for accurate results of the monthly tables; the differences, however, are not considerable. I have also added a scale of the prevailing winds; and to the mean monthly temperatures at $10 \mathrm{~A} . \mathrm{M}$. and 10 P.M., I have applied corrections, which are the differences between the monthly mean temperatures at $10 \mathrm{~A}$.M. and 10 P.M. at Kinfauns Castle, North Britain; and the monthly mean temperatures by a Six's thermometer at that place for 1823, being the nearest to Wick, where a register of the weather was kept at the same hours of observation. The application of these differences as corrections to the monthly mean temperatures at Wick at 10 A.M. and 10 P.M., ought to make the averages nearly as correct as if a Six's thermometer had been used there for that purpose. 